\title{
O DESENHO INFANTIL SOB A ÓTICA DE ARISTÓTELES E PLOTINO
}

\section{CHILDREN'S DRAWING FROM THE PERSPECTIVE OF ARISTOTLE AND PLOTINUM}

\author{
Fernanda Marcucci ${ }^{1}$
}

\section{RESUMO}

Este artigo propõe uma análise sobre o desenho infantil, usando como parâmetros as obras de Aristóteles e Plotino, especialmente a obra "A Poética" do primeiro autor. Para tanto, o objetivo é dissertar sobre o desenvolvimento do desenho ao longo da infância e por meio dele mostrar como os filósofos antigos como Aristóteles e Plotino dizem muito em suas obras sobre a arte atual, principalmente aquela trabalhada na escola.

PALAVRAS-CHAVE: Desenho infantil. Aristóteles. Plotino.

\section{ABSTRACT}

This article proposes an analysis of children's drawing, using as parameters the works of Aristotle and Plotinus, especially the work "A Poética" by the first author. Therefore, the objective is to discuss the development of drawing throughout childhood and, through it, show how ancient philosophers such as Aristotle and Plotinus say a lot in their works about current art, especially that worked at school.

KEYWORDS: Children's drawing. Aristotle. Plotinus.

\footnotetext{
${ }^{1}$ Graduação em Pedagogia pela Universidade Federal de São Paulo (UNIFESP), Mestrado em Educação e Saúde pela Universidade Federal de São Paulo (UNIFESP), Doutorado em Educação e Saúde pela Universidade Federal de São Paulo (UNIFESP), com período de sanduíche na Université Sorbonne Nouvelle (Paris III). Docente no curso de Pedagogia da Universidade Guarulhos (UNG), Coordenadora ENADE na Univeritas UNG, Mediadora de Disciplina no Projeto Ubíqua do Grupo Ser Educacional.
} 


\section{INTRODUÇÃO}

Este trabalho tem por objetivo dissertar sobre o desenvolvimento do desenho ao longo da infância e por meio dele mostrar como os filósofos antigos como Aristóteles e Plotino dizem muito em suas obras sobre a arte atual, principalmente aquela trabalhada na escola.

A presente dissertação tem como foco o desenho infantil e suas fases de desenvolvimento que são embasadas por teóricos do campo da educação que estudaram a arte e o desenho das crianças. A abordagem deste tema não tem apenas como fim o desenho em si, mas é também julgado sob a ótica de grandes filósofos como Aristóteles e Plotino.

Os principais conceitos tratados são os de mimese e o belo no tratado de Aristóteles: "A Poética". No decorrer da dissertação são apresentados o modo como a mimese para este filósofo se encaixa nas práticas de ensino de Arte no Brasil e nos desenhos infantis, além de uma breve explanação sobre o belo e a poiésis. Já em Plotino, busca-se o ideal de beleza, o que encontramos também nos ideais buscados pelos professores da Educação Infantil (0 a 5 anos) e do Ensino Fundamental (6 a 10 anos).

Iniciamos o trabalho com as fases do desenho, acarretando discussões mais amplas utilizando-se dos conceitos colocados acima e outros. Por fim, terminamos nas considerações finais com um pequeno exemplo de como a Arte e o desenho ficam estagnados por muito tempo durante nossa vida, após a infância.

O desenho infantil apresentado sob a ótica de Aristóteles e Plotino: Há uma busca constante, dos professores, pela reprodução perfeita e fiel da realidade nas produções infantis?

"Antes eu desenhava como Rafael, mas precisei de toda uma existência para aprender a desenhar como as crianças" (PICASSO).

O desenho é uma das primeiras linguagens que a criança tem acesso e este começa a ser produzido, mesmo que por meio de garatujas, antes que elas entrem na escola e se alfabetizem. Desde muito cedo podemos notar que elas começam a rabiscar diversos suportes, desde aqueles mais usuais como cadernos e livros, como também paredes, portas, janelas, roupas. "O desenho é para a criança uma linguagem como o gesto ou a fala. A criança desenha para poder registrar a sua fala. Para escrever. O desenho é sua primeira linguagem (ALBANO, 2012, p. 20).

A criança e o seu desenho passam por etapas e fases de desenvolvimento, essas são marcadas por algumas características estudadas por teóricos como Luquet (1969), Vygostky (2009) e Lowenfeld (1957) no campo da Educação. Paralelamente a essas fases de desenvolvimento do desenho infantil, serão abordados o conceito de mimese sob as considerações de Aristóteles em sua obra A Poética.

Apesar de não ser considerado um estágio por Vygotsky (2009), não é possível tirar a garatuja desse trabalho, pois é a primeira construção de desenho da criança. A garatuja, segundo este mesmo autor, não passa de rabiscos sem simetria e que não possuem forma. É neste momento que a criança

é apenas movimento. E a garatuja vai se modificando, conquistando novos movimentos, que de longitudinais vão se arredondando, tornando-se circulares, se enovelando, se espiralando. Em seguida, este espiral-novelo começa a se destacar e surgem os círculos soltos, as bolinhas (ALBANO, 2012, p. 27).

Uma observação importante a ser feita nesse momento é que enquanto as crianças estão produzindo garatujas, muitas professoras e/ou pais ao se depararem com tais rabiscos, acreditam e reproduzem o discurso de que seus alunos não desenham nada, porém até mesmo nas garatujas há significações, pois mesmo que as crianças, aparentemente, não queiram dizer alguma coisa com aqueles desenhos, há que perceber que a forma como dispõem os rabiscos nos papéis dizem muito sobre a singularidade de cada criança. 
[...] diferenças individuais que já aparecem nas garatujas: crianças que ocupavam a folha toda, as que escolhiam apenas um cantinho do papel, as que riscavam com força e os rabiscos fracos dos que pegavam no lápis com cuidado. Vimos que já é possível reconhecer cada criança por sua maneira de garatujar e que numa mesma classe há crianças em vários estágios de garatujar (ALBANO, 2012, p. 30).

Importante destacar que ainda nas garatujas as crianças não se preocupam com as cores e utilizam as que estão mais próximas de seu corpo e de sua produção, assim como afirma Albano (2012), a cor aparece "por acaso e não por necessidade" (2012, p. 27).

A primeira fase propriamente dita do desenvolvimento do desenho é aquela em que a criança deixa de lado os rabiscos sem grandes significações e apesar dos traços não serem muito diferentes das garatujas, a diferença desse estágio se dá na nomeação do desenho por parte das crianças. Quando questionadas sobre o que se trata seu desenho, elas os nomeiam de acordo com representações que elas têm dos objetos e coisas de seu cotidiano, mas essa nomeação pode mudar de acordo com a vontade da criança, portanto hoje ela pode dar um nome ao seu desenho e amanhã outro. "Estes nomes variam sempre: o que era um elefante dali a instantes pode ser um carro; contudo, está presente a intenção de dizer algo" (ALBANO, 2012, p. 29).

Teóricos como Vygotsky (2009) acreditam que seja nesse estágio que a criança desenha pela memória e não por observação, é comum encontrarmos nas produções infantis, pessoas com apenas cabeça e pernas, classificados por esse mesmo autor como "seres esquemáticos desenhados pela criança no lugar da figura humano" (2009, p. 107).

Iniciamos então as alusões à mimese segundo Aristóteles a partir dessa fase do desenho infantil. Como foi dito anteriormente, a criança nesse primeiro estágio desenha por memória e só podemos memorizar algo a partir de uma observação sobre determinado objeto ou pessoa, e então reproduzimos aquilo que vimos e memorizamos. Nesse caso, quando produz algum desenho em virtude de sua memória, a criança já passa a utilizar a mimese. Apesar de Aristóteles não dissertar sobre o desenho infantil, ele reflete em "A Poética" que a imitação é intrínseca ao homem, ou seja, mesmo que não queira, o homem está imitando pois isso faz parte de sua natureza.

Ao que parece, duas causas, e ambas naturais, geraram a poesia. O imitar é congênito no homem (e nisso difere de outros viventes, pois, de todos, é ele o mais imitador, e, por imitação, aprende as primeiras noções (ARISTÓTELES, 1979, p. 1448 b).

Nesse excerto retirado da obra de Jeanne Marie Gagnebin (1997) podemos compreender então que não é por acaso que a criança começa a desenhar se utilizando da mimese, visto que esta é uma forma de aprendizagem específica do homem e por meio dela, a criança passa a se apropriar da natureza a sua volta e praticar a mimese em suas primeiras produções artísticas, mesmo que não sejam fidedignas e semelhantes ao real.

O próximo estágio do desenvolvimento do desenho infantil é aquele em que surgem as formas e linhas, há uma vontade maior em produzir desenhos mais detalhados e com "uma disposição mais verossímil de partes isoladas do objeto: ocultações impressionantes como a do torso não são mais percebidas, todo o desenho aproxima-se da aparência real do objeto (VYGOTSKY, 2009, p. 110).

No terceiro estágio, a criança passa a desenhar com uma forma muito mais verossímil e real do que anteriormente. É nessa fase que as crianças buscam um maior realismo em suas produções, tanto na forma de seus desenhos como também nas cores, eles procuram utilizar as cores de acordo com os objetos que estão desenhando, não pode se distanciar do real.

Ao pensar nesses dois estágios de desenvolvimento dos desenhos infantis, podemos remeter a preocupação de Aristóteles com a mimese em "A Poética", porque para esse filósofo a pergunta principal não é o que deve ser imitado e sim o modo, como se imitar. Isso é uma característica das duas fases apresentadas acima, pois a criança não está preocupada com o que reproduzir, mas sim o modo como vai reproduzir, tentando se aproximar ao máximo da realidade. 
Aristóteles não pergunta o que deve ser representado/imitado, mas como se imita. Pergunta pela capacidade mimética do homem, pelo mimesthai no qual se enraíza a poietiké, entendida como criação de uma obra artística. A poética de Aristóteles também será normativa, como todas as estéticas clássicas, mas as suas normas advêm do emprego apropriado das palavras, dos ritmos, da trama à finalidade de beleza da obra, não em vista da sua fidelidade a um modelo exterior (GAGNEBIN, 1997, p. 84).

Ao transpormos esse conceito para a Educação e ao ensino da Arte nas escolas brasileiras, há uma grande recusa, por parte dos professores polivalentes e especialistas, de um desenho que foi reproduzido, visto que muitas vezes procuram nas produções infantis cópias fidedignas do real e se esquecem que o importante não é a "fidelidade a um modelo exterior" (GAGNEBIN, 1997, p. 84), mas o modo como fazem isso, exatamente como foi dito acima por Gagnebin (1997).

A crítica que se estabelece em relação à imitação, mimese para Aristóteles, é quando ela se dá em relação ao desenho da professora ou do adulto, ao olharem o que foi desenhado pela professora no quadro, acreditam que aquele seja o modelo ideal de desenho e se esforçam para produzirem algo semelhante ou igual. "A aprendizagem se dá através da mimese - cópia de modelos e do natural - pela repetição mecânica de modelos, e não por imitação ativa sobre o modelo da natureza ou da cultura" (IAVELBERG, 2003, p. 110).

Porém, esse tipo de imitação é considerado pelos estudiosos do desenho infantil como errônea, porque a criança começa a ter um ideal de representação irreal e passa a acreditar que não sabe desenhar, porque não o faz como sua professora ou mesmo como seus colegas, que são vistos como desenhistas e muito bons em desenho. Para Viktor Lowenfeld (1957) não podemos, como professores, impor nossas próprias criações aos nossos alunos. "Nunca apresentem o trabalho de uma criança como exemplo para outra. Nunca deixem a criança copiar nada (LOWENFELD apud COX, 2007, p. 237).

É nesse momento que a criança começa a ficar insatisfeita com seus desenhos e produções e para de desenhar e dificilmente passa para o quarto estágio, como bem apresenta Cox (2007) abaixo:

Os problemas começam a aparecer na faixa de oito a dez anos. Como vimos anteriormente, é aí que as crianças começam a ficar insatisfeitas com seu trabalho e substituem suas antigas tentativas ousadas e mais cheias de confiança por desenhos um tanto detalhados e meticulosos, evidencia-se muito a dependência das linhas feitas com régua e do uso da borracha (COX, 2007, p. 238).

A ênfase dada aos desenhos mimeografados e xerocados faz com que a criança se sinta inferiorizada, pois seu desenho dificilmente será semelhante ao que a professora usa e/ou faz. A não ser que se utilize papel vegetal ou coloque a folha por cima do desenho para que este fique idêntico ao original. A criança deixa de desenhar quando a professora começa a trazer desenhos para que ela pinte, pois acha que o desenho do seu professor é muito mais perfeito que o dele(a).

A uniformidade que encontramos em desenhos de crianças de uma mesma classe. Todos temos na lembrança as casinhas, os coelhos e os outros modelos que são repetidos incansavelmente por todas as crianças numa sala de aula; sejam estes desenhos copiados da lousa ou xerocados pelas professoras para colorirem. E ninguém percebe que estas são atividades puramente mecânicas, que nada contribuem para o desenvolvimento das crianças (ALBANO, 2012, p. 71).

O ideal de perfeição dos desenhos esperado pelas professoras vai de encontro com o conceito de mimese proposto por Aristóteles, pois o que encontramos é um desejo incansável pela reprodução idêntica a real, o que dificilmente você encontrará em alguma produção humana.

É importante destacar que para Aristóteles a tragédia mais bela é aquela que cumpre seu fim, considerando a tragédia como uma poesia, e consequentemente como poiésis. Admitimos neste trabalho o conceito de poiesis de 
Nunes (1999, p. 12), em que é a

criação que organiza, ordena e instaura uma realidade nova, um ser. Criação não é, porém, no sentido hebraico de fazer algo do nada, mas na acepção grega de gerar e produzir dando forma à matéria bruta preexistente, ainda indeterminada, em estado de mera potência.

Utilizando-se deste conceito de poiesis, o desenho infantil é uma obra de arte e para aqueles que estudam o desenho no campo da educação, a importância se dá no processo de produção e assim como para esse filósofo, o belo é aquele desenho que cumpriu seu papel, por mais distante que estivesse do real, se a criança se expressou e se utilizou de diversas linguagens para produzir aquele desenho, então pode ser considerado como um desenho belo e nem sempre o mais belo é o que se deteve em copiar exatamente o que estava posto.

Para ampliar a discussão acerca da perfeição buscada nas obras infantis, podemos utilizar Plotino, que apesar de ter outra visão sobre a mimese, é relevante trazê-lo para tratar sobre o ideal de beleza posto em suas obras. "Tudo que tem forma, diz Plotino, é belo e dotado da máxima realidade. O feio, para ele, identifica-se com a ausência de forma: é a negação do real, como ser perfeitamente determinado" (NUNES, 1999, p. 16).

Quando a criança entra na escola, há uma ruptura com o desenho e a arte em geral. A rotina e os horários mudam e ela deixa de desenhar e quando isso acontece é em sua aula de educação artística, que a professora tem em torno de 50 minutos para dar sua aula. Apesar desse tema ser um grande debate, não cabe a nós neste momento explicar sobre isso, porém a entrada na escola marca um período de mudanças na vida do aluno e o que normalmente era feito sem regras, para expressar seus pensamentos, suas vontades e/ou até mesmo brincadeiras passam a ser considerados inferiores. Na escola os traços já não são mais livres como anteriormente, e mesmo que faça parte do desenvolvimento da criança passar pelos estágios em que a mimese impera, não há como obrigar o aluno a ter um traço reto e perfeito aos 8 anos de idade, por exemplo. Os desenhos ganham simetria e o uso da régua e borracha é constante, todo esse problema gira em torno de um outro que é chamado "desenho pedagógico" (ALBANO, 2012, p. 73).

Os desenhos pedagógicos - usados por alguns professores em aula - assim como muitos dos desenhos encontrados nos livros didáticos, são bastante simplificados e atendem a uma ideia abstrata do objeto. E assim o desenho vai perdendo a significação para a criança. Como em geral este adulto já perdeu o seu próprio desenho, o desenho pedagógico se apresenta como um recurso, é para ele mera cópia. Fecha-se assim uma cadeira de desenhos sem significados. Desenhos que não são a expressão de quem deseja desenhar e, portanto, não são nada, pois que arte é sempre linguagem carregada de significado (POUND apud ALBANO, 2012, p. 74).

É interessante notar que um tratado, datado de meados de 250 d.C. podem ser tão atuais para analisar o ensino de arte no Brasil e principalmente o desenho infantil nas escolas brasileiras, apesar de não podermos tirar Plotino de seu contexto, o que postulou ainda faz alusão à diversas realidades encontradas em nosso país.

Há, ainda, muito mais elementos que utilizar em Plotino para tratar da Arte na Educação, porém neste momento foi colocado no texto para complementar a hipótese de que apesar das crianças sentirem prazer em desenhar, a escola rompe com essa criatividade e prazer, levando-os a uma forma fechada de desenho, que prioriza a simetria, imitação desmedida do desenho do professor e dos seus colegas que desenham melhor, segundo seus professores.

\section{CONSIDERAÇÕES FINAIS}

Como vimos no transcorrer do texto, as crianças vão deixando de desenhar porque nas escolas há outras prioridades, que são consideradas mais importantes que o ensino da arte e o desenho em si. Por essa trégua no 
ato de desenhar e de expor seus pensamentos em suas produções que nos deparamos com adultos tão reprimidos artisticamente e com traços muito parecidos aos das crianças de 6 a 8 anos. São inúmeros os motivos pelos quais a criança rompe com o desenho nessa idade, que foram explicitados acima, e só voltam a desenhar quando adultos.

A escola transforma nossas crianças em robôs que servem para reproduzir modelos socialmente construídos e considerados pedagógicos e fundamentais no processo de ensino-aprendizagem. Há características que permanecem muito fortes na escola e na formação e pensamento dos professores, ver o desenho não como uma expressão artística do pensamento e da brincadeira da criança, mas algo muito menor que deve ser perfeito, fiel ao real e sendo contrária ao conceito de mimese estabelecido por Aristóteles, que acreditava que a criança é a prova de que a imitação é a base por excelência. Não é imitar simplesmente por imitar e nem imitação de qualquer objeto, mas sim o modo como deve ser feita essa imitação.

Em uma visita recente à 30a Bienal de Arte Contemporânea de São Paulo, pude comprovar a hipótese de que as crianças param de desenhar em certa idade e só voltam a desenhar quando adultos, quando em uma das instalações, do artista argentino Martín Legón, continham dezenas de desenhos que à primeira vista aparentam ser desenhos infantis, porém ao ler a descrição da obra deu-se conta de que eram obras de adultos que estavam participando de um processo seletivo de uma empresa, para se tornarem futuros funcionários dela. $\mathrm{O}$ desenho proposto pela equipe era um homem debaixo de chuva com um guarda-chuva aberto, e a partir do desenho desses candidatos foram feitas várias afirmações sobre a personalidade dessas pessoas que estavam ali concorrendo à vaga. Esse exemplo mostra bem o que foi dito de que por causa dessa ruptura com o desenho que a maioria das crianças têm em nossas escolas, quando se tornam adultas conservam os traços infantis e mostram muita insegurança ao desenhar, acreditando que não sabem ou que não tem talento para as artes visuais em geral, devido a todo histórico escolar por qual passaram.

\section{REFERÊNCIAS BIBLIOGRÁFICAS}

ALBANO, A. Espaço do desenho: a educação do educador. São Paulo: Loyola, 2012.

ALEXANDROF, M. Os caminhos paralelos do desenvolvimento do desenho e da escrita. Disponível em: <http://pepsic.bvsalud.org/scielo.php?script=sci_arttext\&pid=S1415-69542010000200003>.

AMINE, R; RELY, L. A Poética infantil em foco. Disponível em: http://www.snh2011.anpuh.org/resources/ anais/14/1329329203_ARQUIVO_1300739739_ARQUIVO_Apoeticainfantilemfoco_RaquelAmineLuciaReily_ ANPUH2011.pdf

COX, M. O desenho da criança. São Paulo: Martins Fontes, 2007.

DUARTE, R. (Org.). O belo autônomo: textos clássicos de estética. Belo Horizonte: Ed. UFMG, 1997.

GAGNEBIN, J. M. Sete aulas sobre linguagem, memória e história. Rio de Janeiro: Imago, 1997.

IAVELBERG, R. Para gostar de aprender arte. Porto Alegre: ARTMED, 2003.

VYGOTSKY, L. S. Imaginação e criação na infância: ensaio psicológico - livro para professores. São Paulo: Ática, 2009. 